\title{
Childhood Acute Myeloid Leukemia
}

National Cancer Institute

\section{Source}

National Cancer Institute. Childhood Acute Myeloid Leukemia. NCI Thesaurus. Code C9160.

Acute myeloid leukemia occurring in childhood. 